\title{
Pulmonary Embolism following Fibrin Glue Application. Can It Be?
}

\author{
Shalendra Singh ${ }^{1}$ Surya Kumar Dube ${ }^{1}$ Bhagya Ranjan Jena ${ }^{1} \quad$ Mihir Prakash Pandia ${ }^{1}$
} ${ }^{1}$ Department of Neuroanaesthesiology and Critical Care, All India
Institute of Medical Sciences, New Delhi, India

J Neuroanaesthesiol Crit Care 2018;5:125-126.

Intracranial cavernous hemangiomas ( $\mathrm{CHs}$ ) are highly vascular tumors, and they have high propensity for bleeding. Fibrin sealants are often used in neurosurgery to achieve hemostasis when other techniques are impractical or ineffective. We report a case of pulmonary embolism probably following fibrin sealant application in a case of intracranial $\mathrm{CH}$.

A woman of age 38 years, weight $48 \mathrm{~kg}$, height $145 \mathrm{~cm}$, and ASA (American Society of Anesthesiologists) physical status 1 presented with recurrent headache with nausea and decreased vision in the right eye for 1 year. She was diagnosed to have a 3.3- $\times 3.1-\mathrm{cm} \mathrm{CH}$ in the right suprasellar region with right optic nerve compression. She was scheduled for resection under general anesthesia in supine position. She did not have any systemic abnormalities, had not undergone any previous surgery, and her routine investigations were normal. A standard anesthesia technique of thiopentone, fentanyl, vecuronium, isoflurane, and oxygen with nitrous oxide was used. The patient had a stable course intraoperatively until surgeons applied fibrin sealant to achieve hemostasis. Just after that, we noticed a fall in end-tidal $\mathrm{CO}_{2}$ $\left(\mathrm{ETCO}_{2}\right.$ ) (drop to $20 \mathrm{~mm} \mathrm{Hg}$ from $33 \mathrm{mmHg}$ in 2-3 minutes) along with tachycardia and hypotension. The patient's airway pressure remained stable. The rapidity of the event led us to assume pulmonary embolism to be the most probable cause of the event. However, it was difficult for us to differentiate between air embolism and other substances causing embolism as we solely relied on $\mathrm{ETCO}_{2}$. The serial arterial blood gas (ABG) tests showed a decrease in $\mathrm{PaO}_{2}$ and an increase in $\mathrm{PaCO}_{2}$. Attempts made to aspirate air through central venous access were unsuccessful. With fluids, blood transfusion, and vasopressor (IV ephedrine), hemodynamics improved and $\mathrm{ETCO}_{2}$ and hemodynamics normalized within next 10 minutes. The remaining procedure was uneventful, and the patient was shifted to intensive care unit (ICU) with tracheal tube in situ. She had a stable ICU stay, and her trachea was extubated after 12 hours. A chest radiograph the next day showed no change in appearance, and she was shifted to the ward the next day.

\section{received}

February 23, 2018

accepted

April 12, 2018

published online

May 18, 2018
Address for correspondence Surya Kumar Dube, MD, DM, Department of Neuroanaesthesiology and Critical Care, Neurosciences Center, All India Institute of Medical Sciences, 7th Floor, New Delhi 110029, India (e-mail: surya.dube@yahoo.co.in).

Our patient had sudden decrease in $\mathrm{ETCO}_{2}$, and the possible causes could be breathing circuit disconnection, venous air embolism (VAE), acute hypotension, and pulmonary embolism due to any cause. ${ }^{1}$ We did not think about VAE to be the cause because of absence of any predisposing factors, that is, incision of noncollapsible vein in presence of subatmospheric pressure in these veins, or during surgeries performed with the patient in sitting position. ${ }^{2}$ Likewise, acute hypotension can cause fall in $\mathrm{ETCO}_{2}$, but the fall is usually gradual. We ruled out breathing circuit disconnection as well. Therefore, the most probable cause was pulmonary embolism from some sources. As there was no predisposing factor or suggestive history of deep vein thrombosis or injury to the long bone or any orthopedics intervention, we ruled out pulmonary thromboembolism, fat embolism, or embolism due to bone cement. With this, our differential diagnosis was narrowed down to pulmonary embolism due to fibrin sealant application.

Fibrin sealant is a mixture of fibrinogen, thrombin, and aprotinin. It is extensively used as a hemostatic, sealing agent, and adhesive agent. FG leads to cessation of bleeding by rapid polymerization within the dilated vessel. ${ }^{3}$ There are reports of pulmonary embolism after the use of fibrin sealant in children with facial hemangima. ${ }^{4}$ Another possibility was anaphylaxis/hypersensitivity due to fibrin sealant use., We ruled out anaphylaxis as there was no previous history of surgery in the patient and the clinical presentation was different. Another important aspect is possibility of air or gas embolism with the use of spay device with the fibrin sealant. ${ }^{5}$ However, we have not used spray devices in our patient. To our knowledge, this is the first case report describing a pulmonary embolism following fibrin glue injection into an intracranial $\mathrm{CH}$. Probably the higher vascularity and dilated venous channels in the tumor facilitated the pulmonary embolism in our case. Pulmonary glue embolism is difficult to diagnose, and the treatment is mostly symptomatic. However, in more severe cases systemic heparinization might be required. ${ }^{6}$ With this case report, we want to emphasize that the anesthesiologist should have a high index of suspicion for

Copyright $\odot 2018$ Indian Society of Neuroanaesthesiology and Critical Care
License terms

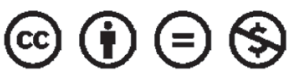

$10.1055 / \mathrm{s}-0038-1654753$. ISSN 2348-0548. 
its occurrence in the setting of hypocarbia, hypoxemia, and tachycardia after injection of fibrin sealant.

\section{Funding}

None.

\section{Conflict of Interest}

None.

\section{References}

1 Bithal P, Dash HH, Vishnoi N, Chaturvedi A. Venous air embolism: does the site of embolism influence the hemodynamic changes? Neurol India 2003;51(3):370-372
2 Muth CM, Shank ES. Gas embolism. N Engl J Med 2000;342(7):476-482

3 Kim IM, Yim MB, Lee CY, et al. Merits of intralesional fibrin glue injection in surgery for cavernous sinus cavernous hemangiomas. Technical note. J Neurosurg 2002;97(3):718-721

4 Orsel I, Guillaume A, Feiss P. [Anaphylactic shock caused by fibrin glue] [in French] Ann Fr Anesth Reanim 1997;16(3):292-293

5 TISSEEL ${ }^{\mathrm{TM}}$ Kit, Two component Fibrin Sealant, Steam - treated. Available at: http://www.baxter.in/healthcare_professionals/ products/tisseel.html. Accessed January 29, 2018.

6 Tonner PH, Scholz J. Possible lung embolism following embolization of a hemangioma with fibrin glue [in German] Anaesthesist 1994;43(9):614-617 